\title{
Synthesis of Silylcyclopropanes through the Catalytic Generation of Zinc Silylcarbenoids from Enynones
}

\author{
Sergio Mata \\ Luis A. López* \\ Rubén Vicente* \\ Departamento de Química Orgánica e Inorgánica and Instituto \\ Universitario de Química Organometálica ‘Enrique Moles', \\ Universidad de Oviedo, c/ Julián Clavería 8, 33006 Oviedo, \\ Spain \\ lalg@uniovi.es \\ vicenteruben@uniovi.es
}

Dedicated to Professor Antonio Echavarren on the occasion of his $60^{\text {th }}$ birthday
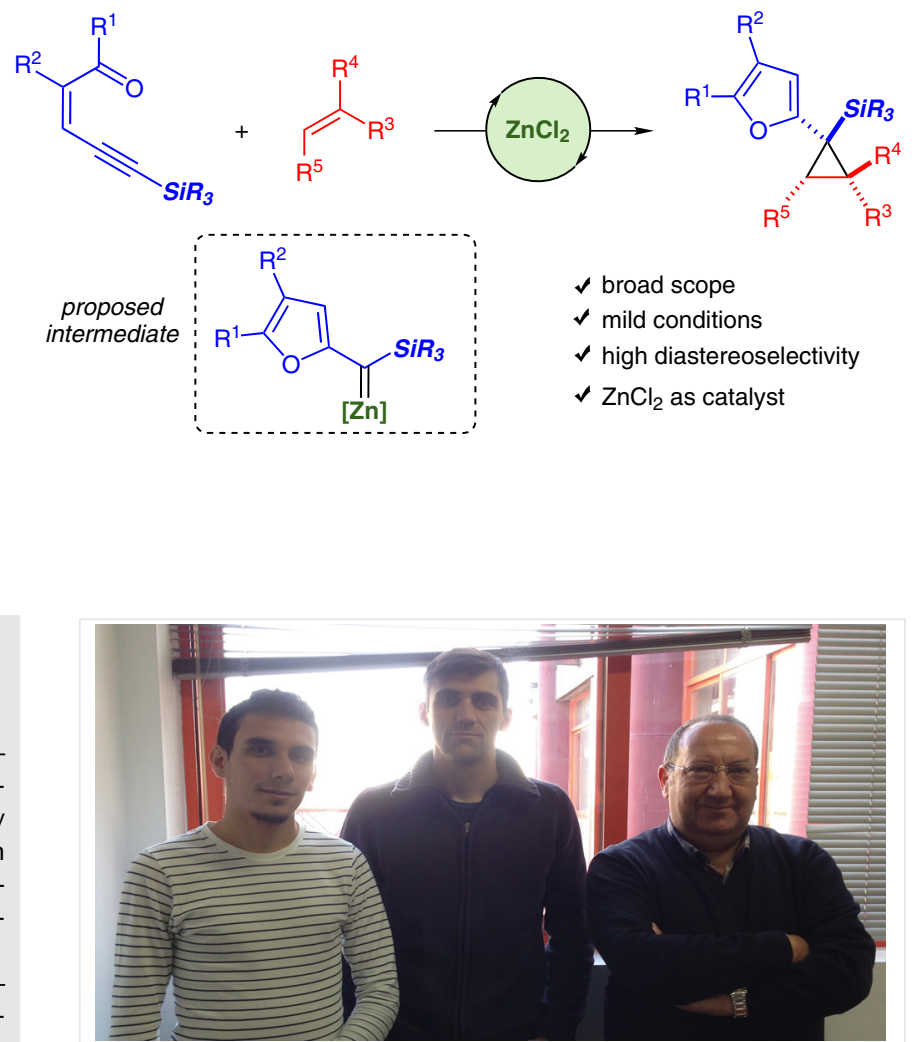

Sergio Mata was born in 1991 in Avilés, Spain. He studied chemistry at the University of Oviedo (2009-2013) and obtained his Master's degree in 2014 with work on the development of new zinc-catalyzed multicomponent processes. He is currently pursuing $\mathrm{PhD}$ studies under the supervision of Dr. L. A. López and Dr. R. Vicente. His work focuses on the use of simple zinc salts as catalysts in organic synthesis.

Luis A. López studied chemistry at the Universidad de Oviedo, where he also earned his $\mathrm{PhD}$ in 1990 working in the field of heterocyclic chemistry under the supervision of Prof. J. Barluenga and Prof. M. Tomás. As an Alexander von Humboldt postdoctoral fellow he then carried out research on group 4 organometallic chemistry at the Organisch-Chemisches Institut der Universität Münster (Germany) with Prof. G. Erker. In 1993, he took a position as a Research Associate at the Universidad de Oviedo, where he was promoted to Associate Professor in 2000. His current research is focused on the development of new selective synthetic methodologies based on the use of transition metal catalysts.

Rubén Vicente studied chemistry at the Complutense University in Madrid. He got his PhD from the University of Oviedo in 2006 with Prof. J. Barluenga, developing synthetic applications of Fischer carbenes. After short research stays at the University of Bonn and Boston College, he spent three years as a Postdoctoral Researcher sponsored by the Humboldt Foundation in the group of Prof. L. Ackermann (Georg-AugustUniversität, Göttingen, 2007-2009), working on C-H bond functionalizations. He returned to Oviedo in 2010 within the 'Juan de la Cierva' program and since 2012 he is a 'Ramón y Cajal' Fellow. In 2014, he was awarded with the Young Investigator Award from the Spanish Royal Chemical Society. His interests include the discovery of new reactivity patterns and sustainable catalysis. 
mercury-containing precursors is required, ${ }^{10}$ or involve the functionalization/manipulation of diazo compounds, which often show low stabilities or are difficult to handle. ${ }^{11,12}$

In the recent years, we have studied the catalytic generation of zinc carbenoids from easily available substrates and their use in synthesis as an alternative to classical stoichiometric protocols. ${ }^{13}$ Taking advantage of the ability of zinc salts to activate alkynes, ${ }^{14}$ we used enynones as carbene source to generate in situ zinc carbene intermediates, ${ }^{15}$ which could be trapped by alkenes leading to the corresponding cyclopropanes. Remarkably, the transformation was accomplished with inexpensive, low-toxicity $\mathrm{ZnCl}_{2}$ as catalyst (Scheme 1, top). ${ }^{13 a}$ In light of these results, we envisioned that the use of properly substituted enynone, specifically when substituent $\mathbf{X}$ is a silyl group $\left(\mathbf{X}=\mathrm{SiR}_{3}\right)$, might serve as the easily available precursor of a functionalized zinc silylcarbenoid intermediate, which eventually would lead to the corresponding silylcyclopropane derivative (Scheme 1, bottom). Herein, we disclose the results of this study.

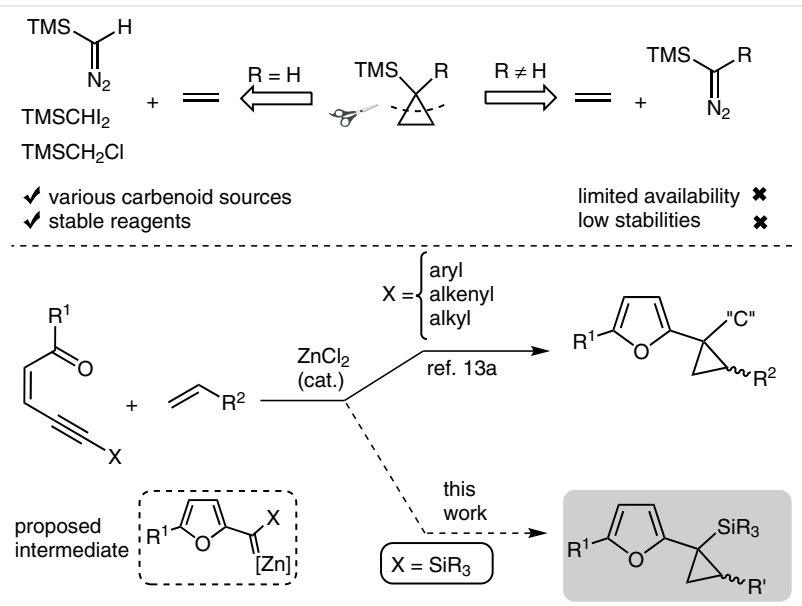

Scheme 1 Synthesis of 1-(silyl)cyclopropanes using silylcarbenoids: existing methodologies (top) and our approach (bottom)

Trimethylsilyl-substituted enynone 1a, directly prepared from commercially available 3-(trimethylsilyl)propiolaldehyde, was selected to test the feasibility of the proposed target. Under the previously described reaction conditions, styrene (2a, 6 equiv), $\mathrm{ZnCl}_{2}$ (10 mol\%) in $\mathrm{CH}_{2} \mathrm{Cl}_{2}(0.1$ $\mathrm{M})$ at ambient temperature, ${ }^{13 \mathrm{a}}$ did not lead to the formation of the-desired silyteyclopropane $3 a(24 \mathrm{~h})$, with the unatteredstarting reagents being the only compounds observed by ${ }^{1} \mathrm{H}$ NMR analysis of the crude mixture (Scheme 2 ). This result could be anticipated considering the steric hindrance of the postulated intermediate that likely encumbers the approach of the alkene for the cyclopropanation. This difficulty could be surpassed with raising the reaction temperature to $50{ }^{\circ} \mathrm{C}$ in 1,2 -dichloroethane (DCE). Under these reaction conditions, silylcyclopropane 3 a was obtained in excellent $90 \%$ isolated yield after 24 hours (Scheme 2). ${ }^{16}$ The transformation occurred with high trans diastereoselectivity (>20:1), in agreement with bulkiness of the trimethylsilyl group. ${ }^{17}$ It is worth mentioning that, to our knowledge, there are no precedents of zinc-mediated synthesis of silylcyclopropanes by means of zinc silyl substituted carbenoids.

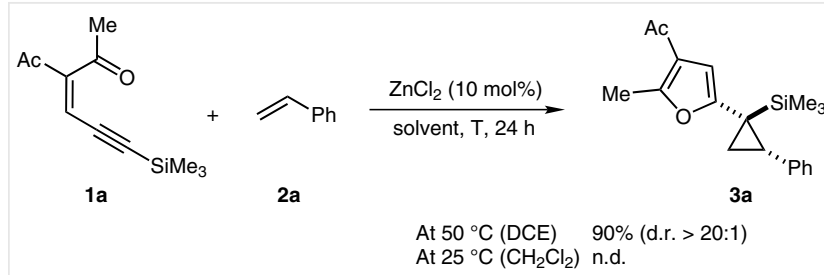

Scheme 2 Zinc-catalyzed synthesis of silylcyclopropane 3a from enynone $\mathbf{1} \mathbf{a}$ and styrene (2a) (n.d. = not detected)

With suitable reaction conditions in hands, we studied the scope of this transformation (Scheme 3$).{ }^{16}$ Styrene derivatives with different electronic properties were evaluated. Under optimized conditions, silylcyclopropanes 3a-d were obtained in good yields (81-90\%) as single diastereoisomers. The use of 4-nitrostyrene led to the cyclopropane 3e in lower yield (49\%) after prolonged heating (50 h). This result agrees with the electrophilic character of the zinc carbene intermediate proposed. ${ }^{13 a}$ 1,1-Disubstituted alkenes could be employed as illustrated with the preparation of compounds $\mathbf{3 f}-\mathbf{j}$. With 1,1-diphenylethene, compound $3 \mathbf{f}$ was obtained in a significant lower yield (35\%) after a long reaction time, probably due to a detrimental effect of the steric hindrance. ${ }^{18}$ Dialkyl-substituted alkenes afforded the cyclopropanes $\mathbf{3 g}-\mathbf{j}$ in acceptable yields, including those with spirane cores in their structures. Importantly, the use of an alkyl monosubsituted alkene such as 1heptene under standard conditions led to the formation of compound 3k in low conversion ( $<30 \%$ conversion, $48 \mathrm{~h}$ ). Despite the low yield, this result is relevant since this kind of alkenes proved unreactive with aryl- or alkyl-substituted enynones. ${ }^{19}$ Gratifyingly, 3k could be isolated in $81 \%$ yield when microwave irradiation was employed as the heating source ( $\mu \mathrm{w}, 120{ }^{\circ} \mathrm{C}, 12 \mathrm{~h}$ ). Moreover, allyltrimethylsilane participated in the reaction leading to the formation of compound 31 (75\%; dr $>20: 1)$. Besides, the reaction with a 1,3-enyne allowed for the synthesis of 2-alkynyl-1-silylcyclopropane $\mathbf{3 m}$ in a good yield (74\%) with complete chemoselectivity for the alkene moiety. The employment of 3,4dihydro-2H-pyran as electron-rich alkene resulted in the diastereoselective formation of alkoxy(silyl)cyclopropane $3 n$ in moderate yield (57\%). ${ }^{20}$ Then, we used enynones bearing different $\mathrm{R}^{1} / \mathrm{R}^{2}$ substituents, which served as zinc carbene source for the cyclopropanations of representative alkenes yielding the corresponding silylcyclopropanes 3o3t with similar efficiencies and complete selectivity. Next, we prepared enynones with silyl groups other than TMS. The reaction of triethylsilyl-substituted enynone with sty- 
rene under the standard conditions for the preparation of cyclopropane $3 \mathbf{u}$ showed low conversion ( $<50 \%$ conversion, $48 \mathrm{~h})$. Again, microwave irradiation $\left(\mu \mathrm{w}, 120^{\circ} \mathrm{C}, 12 \mathrm{~h}\right) \mathrm{im}-$ proved the results enabling the preparation of compound $3 \mathbf{u}$ in a reasonable yield (60\%). More sterically hindered tert-butyldimethylsilyl-substituted enynone was also tested leading to $\mathbf{3 v}$ in lower yield (38\%). Finally, cyclopropanes bearing $\mathrm{PhMe}_{2} \mathrm{Si}$ and $\mathrm{BnMe}_{2} \mathrm{Si}$ substituents $(3 \mathbf{w}-\mathbf{x})$ were prepared in very good yields ( $88 \%$ and $94 \%$, respectively) under standard conditions.
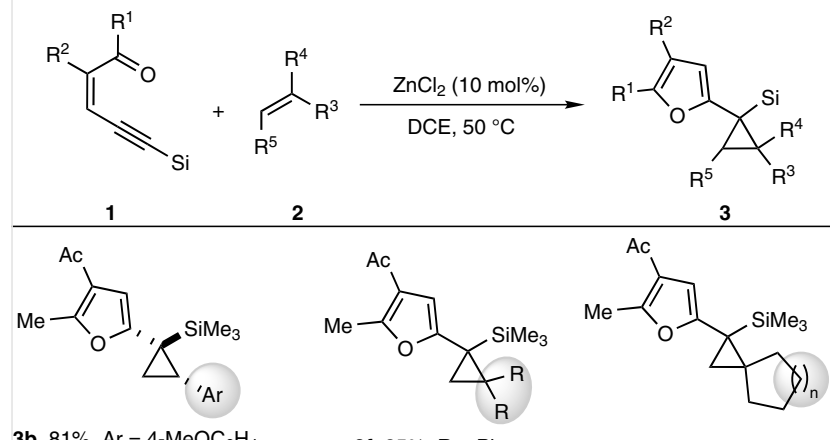

3b, $81 \%, \mathrm{Ar}=4-\mathrm{MeOC}_{6} \mathrm{H}_{4}$ 3c, $87 \%, \mathrm{Ar}=4-\mathrm{AcOC}_{6} \mathrm{H}_{4}$ 3d, $85 \%, \mathrm{Ar}=4-\mathrm{ClC}_{6} \mathrm{H}_{4}$ 3e, $49 \%, \mathrm{Ar}=4-\mathrm{O}_{2} \mathrm{NC}_{6} \mathrm{H}_{4}$

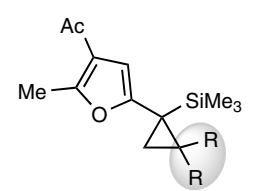

3f, $35 \%, \mathrm{R}=\mathrm{Ph}$ 3 g, $51 \%, R=E$

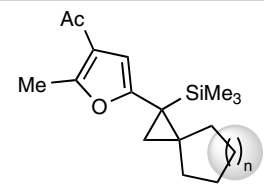

3h, $75 \%, \mathrm{n}=0$ 3i, $65 \%, n=1$ 3j, $64 \%, n=2$<smiles>CCCCCC=CC1C[C@@]1(C)c1cc(C)c(C)o1</smiles><smiles>CCC1CC1([As])c1cc(C)c(C)o1</smiles>
31, $75 \%$

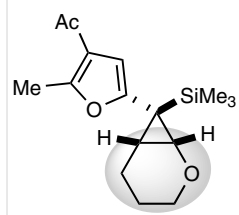

3n, $57 \%$

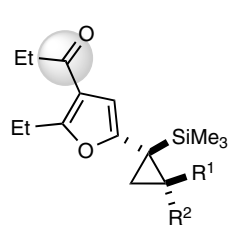

3o, $97 \% \quad R^{1}=H ; R^{2}=P h$ 3p, $77 \% \quad R^{1}-R^{2}=-\left(\mathrm{CH}_{2}\right)_{4}^{-}$ 3q, $85 \% \mathrm{R}^{1}=\mathrm{H} ; \mathrm{R}^{2}=\mathrm{CH}$<smiles>Cc1cc([C@]2([Si])CC2c2ccccc2)oc1C</smiles>

3u, $60 \%$, [Si] $=$ TES $^{\mathrm{a}}$ 3v, 38\%, [Si] = TBDMS $^{\mathrm{a}}$

$3 \mathbf{w}, 88 \%,[\mathrm{Si}]=\mathrm{SiPhMe}_{2}$ 3x, $94 \%$, [Si] $=\mathrm{SiBnMe}_{2}$

Scheme 3 Zinc-catalyzed synthesis of silylcyclopropanes 3: scope. Isolated yields are given. ${ }^{\text {a }}$ Reaction was performed under microwave irradiation $\left(120^{\circ} \mathrm{C}, 15 \mathrm{~h}\right)$.

In addition, we preliminarily explored the reactivity of conjugated dienes as the alkene counterpart. In this case, treatment of benchmark enynone 1a with an excess of 1,3butadiene (4a) under standard conditions led to the formation of bicycles $\mathbf{5 a}, \mathbf{b}$ ( $45 \%$ combined yield, not optimized), arising from a formal [4+3] cycloaddition with partial desilylation (Scheme 4$).^{21}$

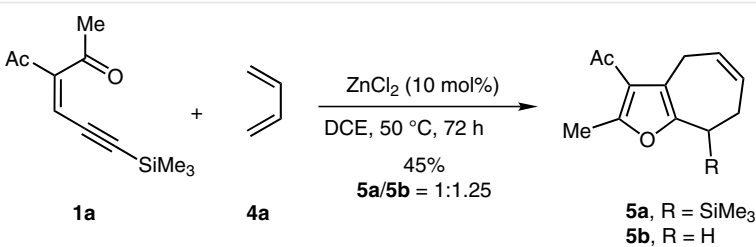

Scheme 4 Reactivity of silyl-substituted enynone $\mathbf{1 a}$ with 1,3-butadiene $4 a$

Finally, we preliminarily attempted the derivatization of cyclopropanes 3 . Using standard reaction conditions for silyl groups removal, representative silylated compounds $\mathbf{3 a}$ and $\mathbf{~ h}$ were transformed into the corresponding cyclopropanes $\mathbf{6 a}$ and $\mathbf{6 h}$ in very good yields, albeit with low diastereoselectivity in the case of $\mathbf{6 a}$ (Scheme 5, top). Moreover, bissilylated compound $\mathbf{3 1}$ was converted into cyclopropane $\mathbf{6 1}$ by chemoselective deprotection of one TMS group. It is noteworthy that the overall process is equivalent to the use of the H-substituted enynone, whose synthesis proved unsuccessful in our hands. Besides, treatment of compound 3w with $\mathrm{HBF}_{4}$ (4.4 equiv) in DCE at $60{ }^{\circ} \mathrm{C}$, led to compound 7 (76\%), in which a phenyl group migrated from silicon to carbon with a concomitant ring opening (Scheme 5, bottom). ${ }^{22,23}$

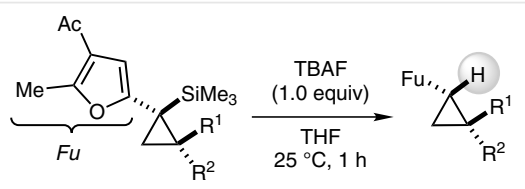

$$
\begin{array}{ll}
\text { 3a, } R^{1}=H ; R^{2}=P h & 6 a, 95 \%(\text { d.r. }=1.5: 1)^{a} \\
\text { 3h, } R^{1}-R^{2}=-\left(\mathrm{CH}_{2}\right)_{4}^{-} & 6 \text { h, 86\% } \\
\text { 3I, } R^{1}=H ; R^{2}=\mathrm{CH}_{2} \mathrm{SiMe}_{3} & 6 \mathbf{6}, 70 \%(\text { d.r. }=1.4: 1)^{\mathrm{a}}
\end{array}
$$

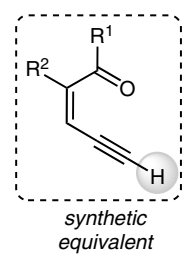

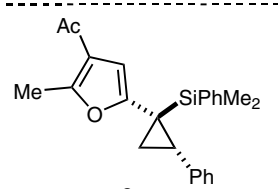

3w

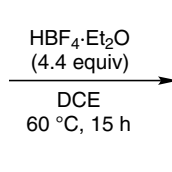

-

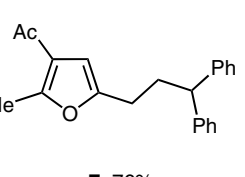

7, $76 \%$
Scheme 5 Derivatization of cyclopropanes 3. ${ }^{[a]}$ Major isomer was not determined.

In summary, we have reported an easy protocol to prepare valuable 1-substituted 1-silylcyclopropane derivatives. This methodology is based on the ability of $\mathrm{ZnCl}_{2}$ to generate a carbene intermediate from enynones capable of reacting with alkenes to afford cyclopropanes. In particular, the silyl substituent attached at the alkyne terminus of the enynone enables the in situ generation of a zinc silylcarbene intermediate, which, to our knowledge, has not been previously proposed in the case of zinc catalysis. This approach operates under mild reaction conditions, avoiding the use of diazo compounds or highly reactive reagents when gen- 
erating the carbenoid intermediate. Importantly, an economical and low-toxicity salt such as $\mathrm{ZnCl}_{2}$ served as catalyst.

\section{Acknowledgment}

Financial support from MINECO of Spain (grant no. CTQ2013-41511P) and the Principado de Asturias ('Severo-Ochoa' Program, fellowship to S.M.) is gratefully acknowledged. R.V. is a Ramón y Cajal fellow.

\section{Supporting Information}

Supporting information for this article is available online at http://dx.doi.org/10.1055/s-0035-1560590.

\section{References and Notes}

(1) (a) Ojima, I.; Li, Z.; Zhu, J. In The Chemistry of Organic Silicon Compounds; Rappoport, Z.; Apeloig, Y., Eds.; Wiley: Chichester, 1998. (b) Auner, N.; Weis, J. Organosilicon Chemistry; WileyVCH: Weinheim, 2003. (c) Fuchs, P. L. Handbook of Reagents for Organic Synthesis, Reagents for Silicon-Mediated Organic Synthesis; Wiley-VCH: Weinheim, 2011.

(2) (a) Paquette, L. A. Chem. Rev. 1986, 86, 733. (b) Krief, A. Top. Curr. Chem. 1987, 135, 1.

(3) For using Simmons-Smith-type carbenoids, see: (a) Seyferth, D.; Cohen, H. M. Inorg. Chem. 1962, 1, 913. (b) Simmons, H. E.; Cairns, T. L.; Vladuchick, S. A.; Hoiness, C. M. Org. React. (N. Y.) 1973, 20, 1. Low yields were commonly obtained due to steric hindrance. Improvements by using alkenes bearing an oxygendirecting group were described, see: (c) Hirabayashi, K.; Mori, A.; Hiyama, T. Tetrahedron Lett. 1997, 38, 461. (d) Imai, N.; Sakamoto, K.; Takahashi, H.; Kobayashi, S. Tetrahedron Lett. 1994, 35, 7045.

(4) For representative examples using metal carbenoids derived from diazo compounds, see: (a) Nasim, M.; Petrosyan, V. S.; Zaitseva, G. S.; Lorberth, J. J. Organomet. Chem. 1992, 430, 269. (b) Berthon-Gelloz, G.; Marchant, M.; Straub, B. F.; Marko, I. E. Chem. Eur. J. 2009, 15, 2923.

(5) (a) Sternberg, E.; Binger, P. Tetrahedron Lett. 1985, 26, 301. (b) Ahra, M.; Grignon-Dubois, M.; Dunoguès, J. J. Organomet. Chem. 1984, 271, 15.

(6) (a) Seyferth, D.; Dow, A. W.; Menzel, H.; Flood, T. C. J. Am. Chem. Soc. 1969, 90, 1080. (b) Hazeldine, R. N.; Scott, D. L.; Titwine, A. E. J. Chem. Soc., Perkin Trans. 1 1974, 1440. (c) Daniels, R. G.; Paquette, L. A. J. Org. Chem. 1981, 46, 2901. (d) Taylor, R. T.; Paquette, L. A. J. Org. Chem. 1978, 43, 242. (e) Ashe, A. J. J. Am. Chem. Soc. 1973, 95, 818.

(7) Olofson, R. A.; Hoskin, D. H.; Lotts, K. D. Tetrahedron Lett. 1978, 1677.

(8) (a) Takai, K.; Hirano, M.; Toshikawa, S. Synlett 2004, 1347. (b) Takai, K.; Toshikawa, S.; Inoue, A.; Kokumai, R.; Hirano, M. J. Organomet. Chem. 2007, 692, 520. (c) Concellón, J. M.; Rogríguez-Solla, H.; Méjica, C.; Blanco, E. G.; García-Granda, S.; Díaz, M. R. Org. Lett. 2008, 10, 349.

(9) For strategies not involving carbene-like precursors, see ref. 2a.

(10) (a) Seyferth, D.; Hanson, E. M. J. Organomet. Chem. 1971, 27, 10. (b) Schollkopf, U.; Rieber, N. Angew. Chem. 1967, 79, 906. (c) Schollkopf, U.; Hoppe, D.; Rieber, N.; Jacobi, V. Justus Liebigs Ann. Chem. 1969, 730.
(11) Aoyama, T.; Shioiri, T. Science of Synthesis; Vol. 4; Fleming, I., Ed.; Thieme: Stuttgart, 2002, 569.

(12) For the preparation of (TMS)phosphinocarbenes, see: (a) Goumri-Magnet, S.; Kato, T.; Gornitzka, H.; Baceiredo, A.; Bertrand, G. J. Am. Chem. Soc. 2000, 122, 4464. (b) Krysiak, J.; Lyon, C.; Baceiredo, A.; Gornitzka, H.; Mikolajczyk, M.; Bertrand, G. Chem. Eur. J. 2004, 10, 1982. (c) For (TMS)thiodiazomethane derivatives, see: Wagner, T.; Lange, J.; Grote, D.; Sander, W.; Schaumann, E.; Adiwidjaja, G.; Adam, A.; Kopf, J. Eur. J. Org. Chem. 2009, 30, 5198.

(13) (a) Vicente, R.; González, J.; Riesgo, L.; González, J.; López, L. A. Angew. Chem. Int. Ed. 2012, 51, 8063. (b) González, J.; López, L. A.; Vicente, R. Chem. Commun. 2014, 50, 8536. (c) González, M. J.; López, L. A.; Vicente, R. Org. Lett. 2014, 16, 5780. (d) Mata, S.; López, L. A.; Vicente, R. Chem. Eur. J. 2015, 21, 8998. (e) González, M. J.; González, J.; López, L. A.; Vicente, R. Angew. Chem. Int. Ed. 2015, 54, 12139.

(14) (a) Mukherjee, A.; Sen, T. K.; Ghorai, P. K.; Samuel, P. P.; Schulzke, C.; Mandal, S. K. Chem. Eur. J. 2012, 18, 10530. (b) For a review, see: González, M. J.; López, L. A.; Vicente, R. Tetrahedron Lett. 2015, 56, 1600.

(15) For representative examples dealing with the generation of furylcarbenes from enynones with other metals, see: (a) Iwasawa, N.; Shido, M.; Kusama, H. J. Am. Chem. Soc. 2001, 123, 5814. (b) Casey, C. P.; Strotman, N. A.; Guzei, I. A. Organometallics 2004, 23, 4121. (c) Hu, F.; Xia, Y.; Ma, C.; Zhang, Y.; Wang, J. Org. Lett. 2014, 16, 4082. (d) For a review, see: Kusama, H.; Iwasawa, N. Chem. Lett. 2006, 35, 1082. (e) For an acid-promoted reaction, see: Clark, J. S.; Romiti, F.; Hogg, K. F.; Hamid, M. H. S. A.; Richter, S. C.; Boyer, A.; Redman, J. C.; Farrugia, L. J. Angew. Chem. Int. Ed. 2015, 54, 5744.

(16) Representative Procedure: To a solution of enynone 1 (0.30 $\mathrm{mmol}$ ) and alkene $\mathbf{2}$ (1.8 mmol, 6.0 equiv) in 1,2-dichloroethane (3.0 mL, $0.10 \mathrm{M}), \mathrm{ZnCl}_{2}(4.0 \mathrm{mg}, 10 \mathrm{~mol} \%$ ) was added at ambient temperature. The Schlenk flask was placed in a preheated oil bath at $50{ }^{\circ} \mathrm{C}$ and the reaction mixture was stirred until consumption of $\mathbf{1}$ (TLC analysis). After elimination of the solvent, purification by flash column chromatography $\left(\mathrm{SiO}_{2}\right.$, hexaneEtOAc) afforded the corresponding cyclopropanes 3. Characterization data for compound 3a: ${ }^{1} \mathrm{H}$ NMR $\left(300 \mathrm{MHz}, \mathrm{CDCl}_{3}\right): \delta=$ 7.05-7.23 (m, $3 \mathrm{H}), 6.92-7.03(\mathrm{~m}, 2 \mathrm{H}), 5.86(\mathrm{~s}, 1 \mathrm{H}), 2.37$ (s, 3 $\mathrm{H}), 2.34$ (dd, $J=7.9,6.1 \mathrm{~Hz}, 1 \mathrm{H}), 2.25(\mathrm{~s}, 3 \mathrm{H}), 1.63(\mathrm{dd}, J=6.0$, $4.8 \mathrm{~Hz}, 1 \mathrm{H}$ ), 1.39 (dd, $J=7.8,4.8 \mathrm{~Hz}, 1 \mathrm{H}$ ), 0.09 (s, $9 \mathrm{H}) .{ }^{13} \mathrm{C}$ NMR $\left(75 \mathrm{MHz}, \mathrm{CDCl}_{3}\right): \delta=194.4(\mathrm{C}), 156.6(\mathrm{C}), 153.9(\mathrm{C}), 138.3(\mathrm{C})$, $127.9(\mathrm{CH}), 127.6(\mathrm{CH}), 125.9(\mathrm{CH}), 121.6(\mathrm{C}), 107.5(\mathrm{CH}), 29.0$ (Me), $26.9(\mathrm{CH}), 17.7(\mathrm{C}), 15.1\left(\mathrm{CH}_{2}\right), 14.2(\mathrm{Me}),-2.9(\mathrm{Me})$. HRMS (ESI): $m / z$ [M] $]^{+}$calcd for $\mathrm{C}_{19} \mathrm{H}_{24} \mathrm{O}_{2} \mathrm{Si}$ : 312.1546 ; found: 312.1543 .

(17) The trans configuration of cyclopropanes 3 was established by NOESY experiments and was not affected during the purification.

(18) Higher temperatures or longer reaction times did not influence the yield.

(19) In the presence of 1-heptene, aryl-substituted enynones underwent a zinc-carbene dimerization, while alkyl-substituted enynones gave rise to complex mixtures.

(20) The use of butyl vinyl ether led to polymerization of the alkene.

(21) (a) For the reactivity of enynones bearing other substituents with related 1,3-diene derivatives, see: Song, B.; Li, L.-H.; Song, X.-R.; Qiu, Y.-F.; Zhong, M.-J.; Zhou, P.-X.; Liang, Y.-M. Chem. Eur. J. 2014, 20, 5910. (b) Signals attributable to the silylcyclopropane were not observed by ${ }^{1} \mathrm{H}$ NMR analysis. Nevertheless, formation of cyclopropane followed by ring expansion cannot be ruled out. 
(22) For related silicon-to-carbon migrations of phenyl groups, see: (a) Fleming, I.; Henning, R.; Plaut, H. J. Chem. Soc., Chem. Commun. 1984, 29. (b) Shintani, R.; Fujie, R.; Takeda, M.; Nozaki, K. Angew. Chem. Int. Ed. 2014, 53, 6546.
(23) Unfortunately, attempts to obtain cyclopropanols by TamaoFleming oxidation (on compounds $\mathbf{3 w}-\mathbf{x}$ ) through various standard procedures failed, leading to complex mixtures or hydrodesilylation product. Various attempts to perform Hiyama couplings were also unsuccessful. 